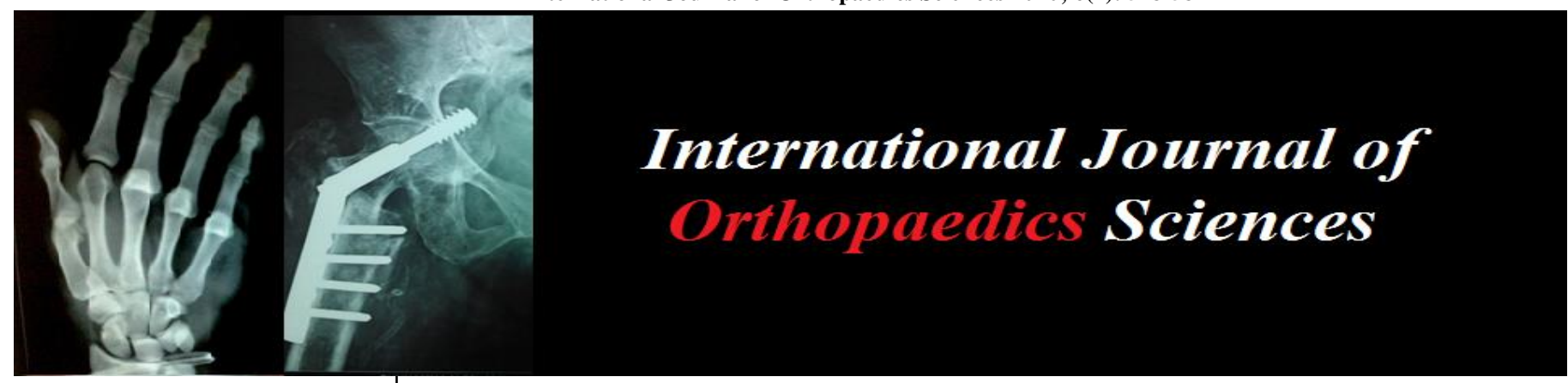

E-ISSN: 2395-1958

P-ISSN: 2706-6630

IJOS 2020; 6(2): 578-581

(C) 2020 IJOS

www.orthopaper.com

Received: 24-02-2020

Accepted: 26-03-2020

Dhaval Pandya

Santokba Durlabhaji Memorial

Hospital, Jaipur, Rajasthan, India

Dr. Kapil Gangwal

Santokba Durlabhaji Memoria

Hospital, Jaipur, Rajasthan,

India

\section{Predictors of functional and radiological outcome of surgical management of bi-malleolar ankle fractures}

\author{
Dhaval Pandya and Dr. Kapil Gangwal
}

DOI: https://doi.org/10.22271/ortho.2020.v6.i2i.2102

\section{Abstract}

1.1 Introduction: Ankle fractures are the most common type of fractures treated by orthopedic surgeons worldwide accounting for around $10 \%$ of all the fractures better understanding of the biomechanics of the ankle, improvements in fixation techniques and findings of outcome studies performed worldwide, there has been a gradual evolution in the effective strategies for the treatment of ankle fractures.

1.2 Aim: To evaluate the functional outcome and results obtained after surgical management by various methods of internal fixation for malleolar ankle fractures with the help of the Baird-Jackson score.

1.3 Material and methods: 30 adult patients with bi-malleolar fractures were treated between January 2017 and December 2017 at a SDM hospital, Jaipur. The inclusion criteria were closed bi-malleolar fractures in skeletally matured patients. Patients with compound fractures, pilon fractures and those with syndesmotic injuries were excluded from the study.

1.4 Results: The mean age of patient was 37.83years. Male and Right side dominant.15 (50\%) cases had road traffic accident as the mechanism of injury. The most common fracture as per the Danis-Weber classification was type B including 16(53.3) cases. 13(43.3) cases had supination external rotation type of injury as per Lauge Hansen classification system, As per the Baird Jackson scoring system, 24 (88\%) cases had good to excellent results, $4(13.3 \%)$ had fair and $2(6.7 \%)$ of the cases had poor results respectively.

1.5 Conclusion: There was no significant difference in outcome on the basis of factors such as side affected, mode of injury, age and sex, type of implant for medial mallelus, Weber type, Lauge and Hansen mechanism. ( $\mathrm{p}$ value $>0.05$ ). There was significant difference in outcome on the basis of factors like post operative complications and implant used for lateral malleolus. ( $p$ value $<0.05$ ).

Keywords: Ankle fractures; medial malleolus; lateral malleolus; TBW; platting; C-C screws

\section{Introduction}

Ankle fractures are one of the most common injuries of the lower limb ${ }^{[1,2]}$. In the recent times, due to the rapid urbanization and change in life style of the people, the incidence of road traffic accidents, sports injuries and fall from height are raising rapidly. Due to this continued trend, people are sustaining injuries and ankle is the one of the most frequently injured areas of the skeleton both in young patients and the elderly ${ }^{[3,4]}$

Management of these fractures depends on careful identification of the extent of bony injury as well as soft tissue and ligamentous damage. A thorough understanding of the ankle anatomy, mechanism of the injury, interpretation of the radiographs and adherence to basic principles of fracture management are the basis for a good outcome.

Surgical reduction and internal fixation has become the mainstay for the treatment of most of the malleolar fractures in all age group. These operative methods restore the anatomy and contact loading characteristic of the ankle including easier rehabilitation, early mobilization and earlier weight bearing ${ }^{[5]}$.

The purpose of this study was to prospectively evaluate patient-reported functional outcomes at six, months following operative treatment of ankle fracture and to identify demographic and patient factors that are associated with functional recovery.

\section{Methodology}

This is a prospective study from January 2017 to December 2017 of 30 adult patients with fractures of bi-malleolar ankle admitted to Santokba Durlabhji Memorial Hospital, Jaipur were
Dhaval Pandya

Santokba Durlabhaji Memoria Hospital, Jaipur, Rajasthan,

India 
taken for this study after obtaining their informed, valid written consent. Closed bi-malleolar fractures in patient above 18 year of age included. Patients with Pilon fractures, Open fractures are excluded.

On admission, careful history and clinical examination and proper radiographs of the affected ankle were taken and the fracture patterns were classified according to the LaugeHansen and Weber's classifications. The limb temporary immobilized in a below knee Plaster of Paris slab till definitive fixation done.

In our study tension band wiring, malleolar screw, $\mathrm{K}$ wires, cancellous screws were used for fixing medial malleolus. One third tubular plate and rush nail were used to fix lateral malleolus.

\subsection{Surgical procedure}

After appropriate anesthesia the patients were placed in supine position with a sand bag under the ipsilateral buttock. Tourniquet was used in all patients. The operative procedure for the fixation was done as per the standard approaches, depending on the mode of fixation planned. The duration of surgery varied from 40 to 65 minutes. The fractures were stabilized with the implants based on AO principles and some modification according to surgeon's preference. After fixation the joint congruency and status of talus was checked and confirmed on IITV. There were no cases of intra-operative complications.

Post operative period a below knee plaster of Paris slab was applied. Radiological evaluation was done in the postoperative period. Patients were mobilized on the first post operative day, non weight bearing with the help of walker. Patients were discharged as soon as general condition allowed. Patients were advised to continue non weight bearing ambulation with a walker or crutches for a period of six weeks.

At the end of 6 weeks the patients were started on active ankle mobilization. Partial weight bearing was stared with support. Weight bearing was decided on the basis of the X-ray picture. Patients were then followed up at 3 months and 6 months. The patients were evaluated as per the rating of the Baird and Jackson ankle scoring system ${ }^{[6]}$ which included functional criteria and Radiological evaluation. These were graded into excellent, good, fair and poor categories. The functional criteria include pain, stability of ankle, motion of ankle, ability to walk, ability to run, ability to work plus radiological grading. Total score is 100 and 100-96- excellent 95-91-good 90-81-fair 80-00- poor.

\subsection{Statistical Methods}

All data analysis was analyzed by SPSS 20 software. Continuous variables were summarized as mean \& standard deviation while nominal/categorical variables as proportion (\%). t-test was used for analysis of continuous variables whereas chi-square test was used for nominal/categorical variables. $\mathrm{P}$-value $<0.05$ was taken as significant.

\section{Results}

The age of the patients ranged from 21 to 75 years with the fracture being most common in the 2 nd to 3rd decade and an average age of $37.83 \pm 15.966$ years due to involvement in sports activity and frequent involvement in road traffic accidents. Out of 30 patients, male were 19(63.33\%) and female were $11(36.66 \%)$ showing male predominance because of travelling and working outfields and factories.15(50\%) patients had road traffic accidents, and 10 $(33.33 \%)$ patients had sports injury. Right side is $17(56.7 \%)$ affected making right side dominant.

(10\%) is type-A, $16(53.3 \%)$ type-B and $11(36.7 \%)$ type-C pattern of injury of Weber classification. According to Lauge and Hansen classification supination external rotation is the most common 13(43.3\%) mode followed by pronation external rotation $10(33.3 \%)$.

In this study for medial malleolus we used TBW for $15(50.0 \%)$ patients making it most commonly used method of fixation followed by one CC screw+ one k-wire in 9(33.3\%), two screws in $5(16.7 \%)$. For lateral malleolus we used plate for $22(73.3 \%)$ patients making it most commonly used method of fixation followed by rush pin in $8(26.7 \%)$.

Joint stiffness is seen in $3(10 \%)$ patient, superficial infection or wound dehiscence in $2(6.7 \%)$ and loss of reduction in $1(3.3 \%)$ patient.

Scoring for clinical outcome (out of 75) was ranging from 56 to 73 with average of 69.3. Scoring for radiological outcome (out of 25) was ranging from 5 to 25 with average of 22.33 . Total score (out of 100) was average 91.27

Table 1: Outcome

\begin{tabular}{|c|c|c|}
\hline Outcome & No. of patients & Percentage \\
\hline Excellent & 4 & 13.3 \\
\hline Good & 20 & 66.7 \\
\hline Fair & 4 & 13.3 \\
\hline Poor & 2 & 6.7 \\
\hline Total & 30 & 100.0 \\
\hline
\end{tabular}

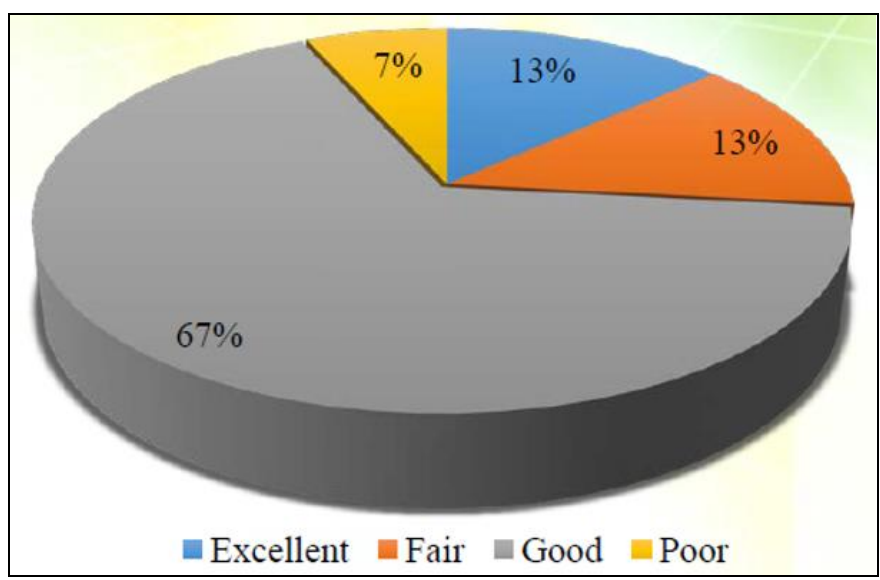

Fig 1: Outcome

By the analysis of the data collected in the present study for the predictors of outcome of surgical intervention of bimalleolar ankle fracture outcome is not dependent on age, sex, side involved, and mode of injury, Weber's type, Lauge and Hansen mechanism or the method of fixation used for medial malleolus. ( $\mathrm{p}$ value $>0.05$ ). However outcome had significant association with method of fixation of lateral malleolus and post-operative complications. ( $\mathrm{p}$ value $<0.05$ ). 


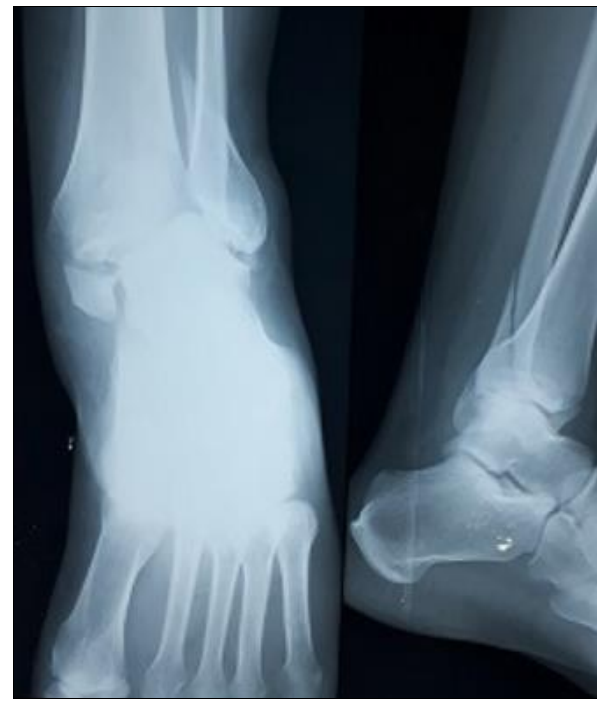

Fig 2: Pre-Op

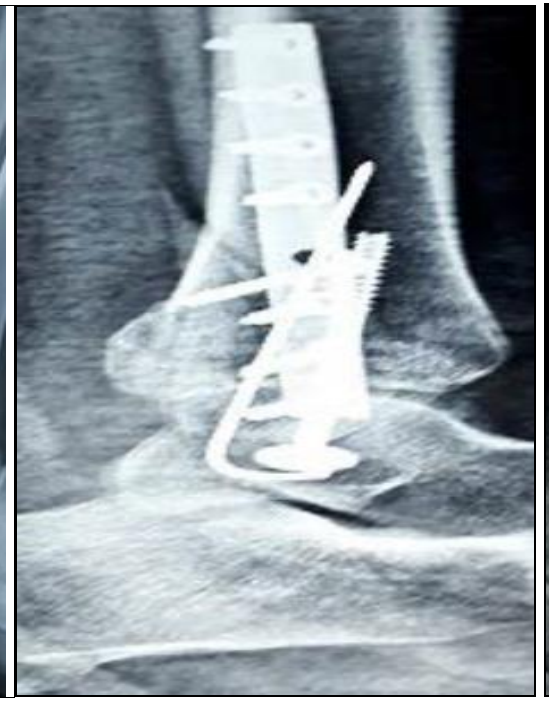

Fig 3: Post op at 6 months (Lateral)

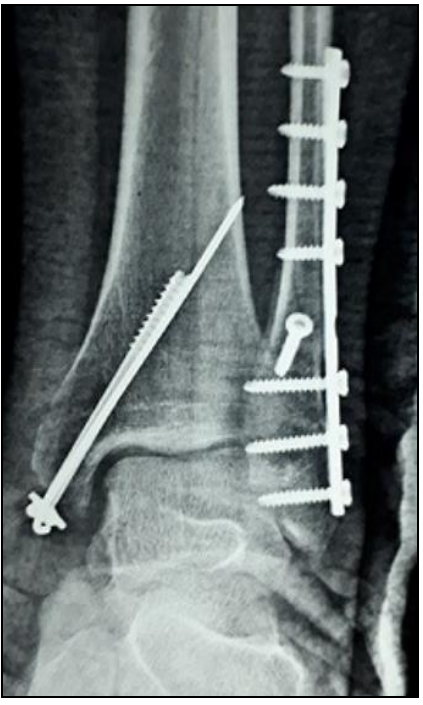

Fig 4: Post op at 6 months (AP)

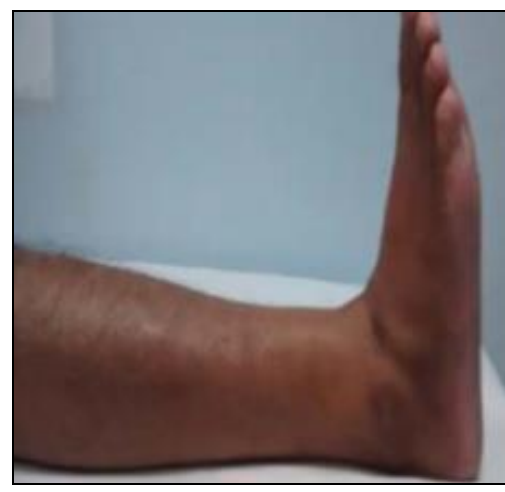

Fig 5: ROM at 6 months Post-Op

\section{Discussion}

Increased knowledge about the normal and post traumatic anatomy and function of the ankle joint has lead to demands for exact reduction and rigid fixation of the ankle fractures. Prompt operative treatment of displaced ankle fractures decreases morbidity and improves functional outcome ${ }^{[5,7]}$. The treatment of malleolar fractures with accurate open reduction and stable internal fixation using $\mathrm{AO}$ method and principles was found to give a high percentage of excellent and good results ${ }^{[8]}$. The status of the soft tissues and the surrounding ligament injuries affect the long term clinical

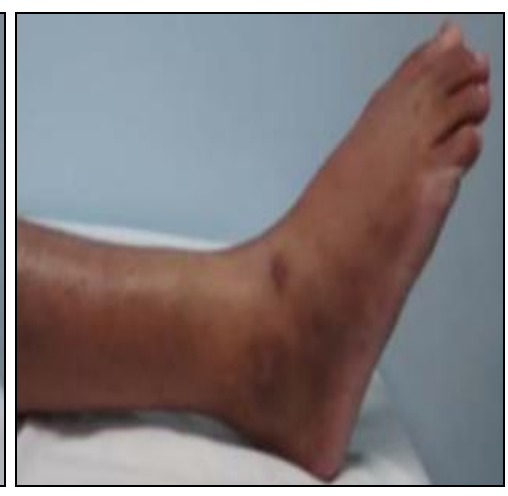

Fig 6: ROM at 6 months Post-Op

results.

The goal of operative treatment is to obtain anatomic realignment of the joint surface, fracture healing and ankle that functions normally without pain while providing enough stability to allow early motion. This should be accomplished using various techniques.

The present study was undertaken to determine various predictors of outcome of surgically treated bi-malleolar ankle fracture using various techniques. We evaluated our results and compared them with those obtained by various other studies utilizing different modalities of treatment.

Table 2: Comparision with other studies

\begin{tabular}{|c|c|c|c|c|c|}
\hline Category & Roberts SR $^{[\mathbf{9 ]}}$ & Baird $^{[\mathbf{6 ]}}$ & Beris $^{[\mathbf{8}]}$ & Lee $^{[\mathbf{1 0}]}$ & Our Study \\
\hline No. of patients & 25 & 24 & 144 & 168 & 30 \\
\hline Mean age (Year) & 40 & 30 & 43 & 44 & 37.83 \\
\hline Sex male (\%) & $44 \%$ & $70 \%$ & $38.88 \%$ & $42.90 \%$ & $63.33 \%$ \\
\hline Right side Involvement (\%) & $56 \%$ & $45.80 \%$ & $73 \%$ & NA & $56.6 \%$ \\
\hline Most common mode of Injury & NA & Fall from height & NA & RTA & RTA \\
\hline Type of injury most common SER & $34 \%$ & $44 \%$ & NA & NA & $43.30 \%$ \\
\hline
\end{tabular}

In this study most common type is Weber's Type B fractures consisted of $53.3 \%$. The findings were similar to those of Liestal $^{[11]}$ and Court brown ${ }^{[1]}$.

Observation in this study support the contention of Yablon ${ }^{12}$ that lateral malleolus is the key to the anatomical reduction of bimalleolar fractures, because the displacement of the talus faithfully followed that of the lateral malleolus. Poor reduction of the lateral malleolus fracture would result in persistent lateral displacement or residual shortening.
Lateral malleolus can be fixed by various methods. Lateral plate, as advocated by AO group has become widely accepted for treatment of fibular fracture ${ }^{[12]}$. Hughes ${ }^{[13]}$ recommended that lateral malleolus should be fixed first.

In this study, the functional outcome was better in patients who underwent stable internal fixation of the medial malleolus by at least one cancellous or malleolar screw. The results were not equally satisfactory in those patients who had less rigid fixation of the medial malleolus using only 
Kirschner wires. Tension band wiring of the medial malleolus gave results equivalent of those fixed with screws and lesser reports of skin irritation which was more frequent in those patients with screw fixation.

In the current study, one patient with poor outcome had failed reduction possibly due to less rigid fixation of the lateral malleolus by rush pin and soft tissue interposition in the medial malleolus.

Table 3: Comparision of Outcome

\begin{tabular}{|c|c|c|c|}
\hline Study & Good to Excellent & Fair & Poor \\
\hline Burnwell \& Charnley $^{[5]}$ & $102(77.3 \%)$ & $22(16.7 \%)$ & $8(6 \%)$ \\
\hline Colton $^{[14]}$ & $18(70 \%)$ & $4(15 \%)$ & $4(15 \%)$ \\
\hline Beris $^{[8]}$ & $105(74.3 \%)$ & $21(14.6 \%)$ & $16(11.1 \%)$ \\
\hline De souza $^{[15]}$ & $135(90.0 \%)$ & $9(6 \%)$ & $6(4 \%)$ \\
\hline Present study $^{24(80 \%)}$ & $4(13.3 \%)$ & $2(6.7 \%)$ \\
\hline
\end{tabular}

The functional results of the present study were comparable with that of the above cited studies, with $80.0 \%$ had good to excellent results, $13.3 \%$ had fair results and poor results in $6.7 \%$.

\section{Conclusions}

We concluded that surgical intervention is a well-documented method which relieves pain and functional disability and improves functional and radiological outcome in patients with bi-malleolar ankle fractures and improving quality of their life.

Most commonly affected age group was young person of 2130. Males predominated in this study compared to female (19:11). Right side was affected more (17:13). Road traffic accidents were the most common mode of injury (15) followed by sports injury (10). According to Weber classifications; type B (16) was the most common followed by type C (11) and type A (3). According to Lauge-Hansen mechanism of injury; Supination-external rotation was the most common mechanism (13).

The functional \& radiological outcome was excellent to good in $80 \%$ cases \& fair in $13.3 \%$ cases as per Baird and Jackson ankle scoring in our study. The complications in our study which we got were superficial skin infection, joint stiffness and loss of reduction.

There was no significant difference in outcome on the basis of factors such as side affected, mode of injury, age and sex, type of implant for medial mallelus, Weber type, Lauge and Hansen mechanism. ( $p$ value $>0.05$ ). There was significant difference in outcome on the basis of factors like post operative complications and implant used for lateral malleolus. ( $p$ value $<0.05)$.

\section{Limitations}

A longer follow-up, larger number of sample sizes and comparative study would have been more beneficial in yielding accurate results and would have more impact on the results.

\section{References}

1. Court-Brown CM, McBirnie J, Wilson G: Adult ankle fractures-an increasing problem? Acta Orthop Scand. 1998; 69(1):43-47.

2. Lash N, Horne G, Fielden J, Devane P: Ankle fractures: functional and lifestyle outcomes at 2 years. ANZ J Surg. 2002; 72(10):724-730.

3. Bauer M, Bengnér U, Johnell O, Redlund-Johnell I: Supination-eversion fractures of the ankle joint: changes in incidence over 30 years. Foot Ankle. 1987; 8(1):26-28.

4. Daly PJ, Fitzgerald RH, Melton LJ, Listrup DM. Epidemiology of ankle fractures. Acta Orthopaedica Scandinavian. 1987; 58:539-44.

5. Burwell HN, Charnley AD. The treatment of displaced fractures of ankle by rigid internal fixation and early joint movement. J Bone Joint Surg.1965; 47(B):634-60.

6. Baird AR, Jackson TS. Fractures of the distal part of the fibula with associated disruption of the deltoid ligament. J Bone Joint Surg. 1987; 69A:1346-52.

7. Lindsojo U. Operative treatment of ankle fracturedislocations. Clin Orthop. 1985; 199:28-38.

8. Beris AE, Kabbani KT, Xenakis TA, Mitsionis G, Soucacos PK, Soucacos PN. Surgical treatment of malleolar fractur es-A review of 144 patients. Clin Orthop Related Research. 1997; 341:90-98.

9. Roberts RS. Surgical treatment of displaced ankle fractures. Clin Ortop. 1983; 172:164-70.

10. Lee Yih Shiunn, Huang, Chun-Chen NSP, Chen, ChengNan, Lin Chien-Chung. Operative treatment of displaced lateral malleolar fractures: The knowles pin technique. J Orthop Trauma. 2005; 19(3):192-7.

11. Hughes JL, Weber H, Willenegger $\mathrm{H}$, Kuner $\mathrm{EH}$. Evaluation of ankle fractures: non-operative and operative treatment. Clin Orthop Relat Res. 1979; 138:111-9.

12. Yablon IG, Heller FG, Shouse L. The key role of lateral malleolus in displaced fractures of the ankle. J Bone Joint Surgery. 1977; 57A:169-73.

13. Hughes J. The medial malleolus in ankle fractures. Orthopaedic Clinics of North America. 1989; 11(3):649660.

14. Colton CL. The treatment of Dupuytren's fracture dislocation of the ankle. J Bone Joint Surg, 1997; 53B:63-71.

15. De Souza LJ, Gustilo RB, Meyer TJ. Results of operative treatment of displaced external rotation-abduction fractures of ankle. J Bone Joint Surg. 1985; 67A:1066-74. 